\title{
A SIMPLE TEST OF PRIVATE INFORMATION IN THE INSURANCE MARKETS WITH HETEROGENEOUS INSURANCE DEMAND
}

\author{
Li Gan \\ Feng Huang \\ Adalbert Mayer \\ Working Paper 16738 \\ http://www.nber.org/papers/w16738 \\ NATIONAL BUREAU OF ECONOMIC RESEARCH \\ 1050 Massachusetts Avenue \\ Cambridge, MA 02138 \\ January 2011
}

The views expressed herein are those of the authors and do not necessarily reflect the views of the National Bureau of Economic Research.

NBER working papers are circulated for discussion and comment purposes. They have not been peerreviewed or been subject to the review by the NBER Board of Directors that accompanies official NBER publications.

(C) 2011 by Li Gan, Feng Huang, and Adalbert Mayer. All rights reserved. Short sections of text, not to exceed two paragraphs, may be quoted without explicit permission provided that full credit, including (c) notice, is given to the source. 
A Simple Test of Private Information in the Insurance Markets with Heterogeneous Insurance Demand

Li Gan, Feng Huang, and Adalbert Mayer

NBER Working Paper No. 16738

January 2011

JEL No. D82,G22,I11

\section{ABSTRACT}

A positive correlation between insurance coverage and ex post risk can be an indicator for private information in insurance markets. However, this test fails if agents have heterogeneous risk attitudes. We propose a new test that conditions on unobserved types of individuals who differ in their risks preferences. This makes it possible to detect asymmetric information without direct evidence of private information - even if agents have heterogeneous risk attitudes. We apply our technique to the market for long-term care insurance. Finkelstein and McGarry (2006) provide direct evidence for the existence of private information in this market. At the same time they fail to find a positive correlation between insurance coverage and ex post risk. Our method indicates the existence of private information, without using direct evidence of private information. Our methodology is applicable to other insurance markets and markets where proxies for private information are not available.

Li Gan

Department of Economics

Texas A\&M University

College Station, TX 77843-4228

and NBER

gan@econmail.tamu.edu
Adalbert Mayer

Department of Economics

Washington College

Chestertown, MD 21620

amayer2@washcoll.edu

Feng Huang

Research Institute of Economics and Management

Southwestern University of Finance and Economics

Chengdu, China

phenix.hf@gmail.com 


\section{Introduction}

Economic theory suggests that the presence of private - or asymmetric - information has important implications on insurance markets. ${ }^{2}$ Adverse selection and moral hazard can lead to a sub-optimal provision of insurance and a decrease in welfare. Therefore, it is important to detect and to quantify the effects of asymmetric information in insurance markets.

One indicator for the presence of asymmetric information is a positive correlation between an individual's risk and the decisions to purchase insurance (after controlling for public information). ${ }^{3}$ This indicator does not require to directly observe private information and it has been used to investigate a number of insurance markets.

The empirical results, however, are mixed and differ by markets. For example, in a life insurance market, Cawley and Philipson (1999) conclude that the mortality rate of U.S. males who purchase life insurance is below that of the uninsured, even when controlling for many factors such as income that may be correlated with life expectancy. In an auto insurance market, Chiappori and Salanié (2000) find that accident rates for young French drivers who choose comprehensive automobile insurance are not statistically different from the rates of those opting for the legal minimum coverage, after controlling for observable characteristics known to automobile insurers.

In contrast, Cohen (2005), using data from Israel, shows that new auto insurance customers choosing a low deductible tend to have more accidents, leading to higher total losses for the insurer. In an annuity insurance market, Finkelstein and Poterba (2004) observe systematic relationships between ex post mortality and annuity characteristics, such as the timing of payments and the possibility of payments to the annuitant's estate, but they do not find evidence of substantive mortality differences by annuity size. He (2009) draws a complete different

2 Rothschild and Stiglitz.(1976)

3 Chiappori (2000) Chiappori and Salanié (2000) 
conclusion with the existing literatures, by producing evidence for the presence of asymmetric information in the life insurance market. In particular, she presents a significant and positive correlation between the decision to purchase life insurance and subsequent mortality, conditional on risk classification.

One existing explanation for failure to detect the private information is the presence of heterogeneous preferences for insurance. De Meza and Webb (2001) suggest that there may be advantageous selection, which means that more cautious people are not only more inclined to purchase insurance but also more likely to put effort in preventing risk exposures. The presence of both adverse selection and advantages selection may create insignificant or even negative correlations between an individual's risk exposure and the decision to purchase insurance even with private information. Finkelstein and McGarry (2006), short F\&MG, introduce variables that measure cautiousness and wealth quartiles. These variables are expected to be correlated with insurance demand and risk exposures. They find that these variables positively related to insurance demand and negatively related risk exposures. They explain this result with the existence of multiple types of insurance costumers. More cautious and wealthier individuals are more likely to purchase long-term care insurance and less likely to enter a nursing home. In other words, the presence of asymmetric information is masked by heterogeneous risk attitudes or heterogeneous insurance demand. However, their framework still fails to find private information even after introducing factors about individual heterogeneity, despite a direct evidence of private information when available.

Fang, Keane and Silverman (2008) also provide evidence of advantageous selection. They find that having Medigap insurance would be associated with $\$ 4,000$ less in total medical expenditure if not controlling for health status, and $\$ 2,000$ more in total medical expenditure if controlling for health status. This result indicates that those who purchase Medigap insurance are healthier, providing evidence of advantageous selection. 
This paper makes three contributions to the literature. First, we identify the reasons for failure to detect the private information in the current empirical framework even in the presence of the factors that are related to individuals' heterogeneity of insurance demand. As discussed in F\&MG, the presence of individual heterogeneity may cause the problem. However, including factors that are related to individual heterogeneity may not solve the problem as long as we only have an incomplete set of factors that explain the individual heterogeneity.

Second, we present an alternative test for the private information in the presence of heterogeneous preferences for insurance. We assume that individuals can be grouped into two types. The timid type has a stronger taste for insurance and is less likely to experience the insured event. The bold type has a weaker preference for insurance and a higher risk of experiencing the insured event. The test of a positive correlation between an individual's risk and the decision to purchase insurance is only valid if conditioning on either type. Since types are not observed, we use the mixture density to jointly model the risk and insurance purchase. Several characteristics that are correlated with the unobserved types are used to probabilistically determine which type the person belongs to. The advantage of this method is that an incomplete set of variables that explain the individual heterogeneity is normally sufficient to produce consistent estimates in the insurance demand and risk exposure equations, and to detect private information if it exists. The literature has been using the mixture density to identify unobserved types. Examples include Lee and Porter (1984), Keane and Wolpin (1997), Knittel and Stango (2003), and Gan and Mosquera (2008). Henry, Kitamura, and Salanié (2010) explain conditions for identification of finite mixtures.

Third, we apply this model to the sample of F\&MG. The advantage of the F\&MG sample is that the direct evidence of private information is available. We find that the two types of agents behave differently as predicted. The timid are more likely to purchase insurance but less likely to enter the nursing home than the bold. Conditional on public information and the type of an individual we obtain a statistically significantly positive correlation between ex post risk and the 
insurance purchases. This provides the evidence of the existence of private information. Allowing for two types of individuals makes it possible to detect the presence of private information. We confirm the finding of F\&MG without relying on direct evidence of private information. Moreover, we also confirm that the timid type would be more likely than the bold type to purchase the insurance policy but less likely to use insurance, as predicted by the theory.

Our method is most useful for insurance markets where such direct evidence of private information is not complete or even not available. It may uncover the existence of private information while simultaneously account for heterogeneity in risk attitudes and reveal the existence of asymmetric information without the direct evidence of private information.

The paper is organized as follows, in section 2 we illustrate the identification problem and explain how it is possible to account for heterogeneity in risk preferences. Section 3 describes the data and presents the results. Section 4 concludes.

\section{An Empirical Strategy to Detect Private Information in the Insurance Market}

We empirically characterize the market for long-term care insurance (LTCI) through two equations. The first equation relates individuals' characteristics to the probability of entering a nursing home. The second equation relates the same characteristics to the decision to purchase long-term care insurance.

$$
\begin{aligned}
& N H=1\left(c_{\beta}+X \beta_{X}+Z \beta_{Z}+H \beta_{H}+u>0\right) \\
& L T C I=1\left(c_{\delta}+X \delta_{X}+Z \delta_{Z}+H \delta_{H}+v>0\right)
\end{aligned}
$$

We use $\boldsymbol{X}$ to denote characteristics that are public information - information that is available to both the individual and the insurance provider. Individuals may have information about the likelihood of eventually entering a nursing home that is not available to the insurer. We denote this private information by $\boldsymbol{Z}$. Without loss of generality we define $\boldsymbol{Z}$ so that $\beta_{Z}>0$. A higher probability of entering a nursing home creates an incentive to purchase long-term care insurance. As $\boldsymbol{Z}$ is not reflected in insurance premiums, this leads to a positive relationship 
between $Z$ and insurance purchases, $\delta_{Z}>0$. Further, we include $H$ to denote individual taste for insurance or individual risk attitude. We define $H$ so that $\delta_{H}>0$, a higher value of $H$ implies a higher likelihood of purchasing insurance. At the same time, as pointed out by de Meza and Webb (2001), and supported by empirical evidence in F\&MG and Fang, Keane and Silverman (2008), a higher value $H$ is associated with a lower level of ex post risk, i.e., $\beta_{H}<0$. While both private information $Z$ and individual heterogeneity $H$ are unobserved, they exhibit different effects on insurance purchase and ex post risk. The coefficients for the private information, $\beta_{Z}$ and $\delta_{Z}$ have the same sign in the equations characterizing insurance purchase and ex post risk. The coefficients for individual heterogeneity, $\beta_{H}$ and $\delta_{H}$, have opposite signs in the two equations. Finally, since all common factors have already been conditioned in (1), the error terms $u$ and $v$ are assumed to be distributed standard normal $u \sim N(0,1)$ and $v \sim N(0,1)$, and are independent on each other, $\operatorname{Cov}(u, v)=0$.

If it is not possible to observe $\boldsymbol{Z}$ or $H$, the two equations can be estimated only partially:

$$
\begin{aligned}
& N H=1\left(c_{\beta}+X \beta_{X}+u^{*}>0\right) \\
& L T C I=1\left(c_{\delta}+X \delta_{X}+v^{*}>0\right)
\end{aligned}
$$

The resulting error terms are given by: $u^{*}=H \beta_{H}+Z \beta_{Z}+u$ and $v^{*}=H \delta_{H}+Z \delta_{Z}+v$. If individuals have homogeneous risk preferences or insurance demand, there is no variation in $H$. The correlation between the error terms is given by:

$$
\operatorname{Cov}\left(u^{*}, v^{*}\right)=\rho_{1}=\delta_{Z}^{\prime} Z^{\prime} Z \beta_{Z}>0
$$

with $\beta_{Z}>0$ and $\delta_{Z}>0$. Therefore, the presence of unobserved private information leads to a positive correlation, and estimating $\rho_{l}$ offers a way to empirically test for the presence of asymmetric information.

However, this test can fail to detect the presence of private information if individuals differ in their inclination to purchases insurance. With heterogeneous risk preferences the correlation of the error terms is described by: 


$$
\rho_{2}=\operatorname{Cov}\left(u^{*}, v^{*}\right)=\underbrace{\delta_{Z}^{\prime} Z^{\prime} Z \beta_{Z}}_{(+)}+\underbrace{\delta_{H}^{\prime} H^{\prime} H \beta_{H}}_{(-)}+\underbrace{\delta_{Z}^{\prime} Z^{\prime} H \beta_{H}+\delta_{H}^{\prime} H^{\prime} Z \beta_{Z}}_{(\text {ambiguous })}
$$

The first term in (4), $\delta_{Z}^{\prime} Z^{\prime} Z \beta_{Z}$, is assumed to be positive in the presence of private information. However, the second term $\delta_{H}^{\prime} H^{\prime} H \beta_{H}$ is negative if $\beta_{H}$ and $\delta_{H}$ have opposite signs. In other words, if individuals with a low risk of nursing home use $\left(\beta_{H}<0\right)$ tend to have a taste for insurance $\left(\delta_{H}>0\right)$, the correlation of the two error terms in (4) is no longer indicative of the presence of asymmetric information, but rather a combination of asymmetric information and heterogeneous taste in insurance. Further, the signs of the remaining two terms in (4) cannot be determined without further assumptions. Without observing $H$ the sign of $\rho_{2}$ in (4) cannot be determined ex ante.

In general it is not possible to observe $H$. However, it may be possible to observe a set of variables $\boldsymbol{W}$ that are related to $H$. F\&MG propose such variables: wealth, adoption of preventive health activities, and seat belt usage. They use these variables to estimate the following model,

$$
\begin{aligned}
& N H=1\left(c_{\beta}+X \beta_{X}+W \beta_{W}+u^{*}>0\right) \\
& L T C I=1\left(c_{\delta}+X \delta_{X}+W \delta_{W}+v^{*}>0\right)
\end{aligned}
$$

If $\boldsymbol{W}$ fully characterizes $H$, the correlation between the error terms can be used to test for private information. However, if $\boldsymbol{W}$ only represents a subset of variables that characterizes $H$, the problem remains. For example, let $H$ be fully characterized by observed $\boldsymbol{W}$ and unobserved $\boldsymbol{M}$ :

$$
H=a \boldsymbol{W}+\boldsymbol{M}+\varepsilon,
$$

then the error tem in the $N H$ model in (5) is $u^{*}=Z \beta_{Z}+M \beta_{H}+\varepsilon+u$, and the error term in the LTCI model in (5) is $v^{*}=Z \delta_{Z}+M \delta_{H}+\varepsilon+v$. The correlation between $u^{*}$ and $v^{*}$ is given by:

$$
\rho_{3}=\underbrace{\delta_{Z}^{\prime} Z^{\prime} Z \beta_{Z}}_{(+)}+\underbrace{\delta_{H}^{\prime} M^{\prime} M \beta_{H}}_{(-)}+\underbrace{\delta_{Z}^{\prime} Z^{\prime} M \beta_{H}+\delta_{H}^{\prime} M^{\prime} Z \beta_{Z}}_{(\text {ambiguous })}
$$

Again, similar to $\rho_{2}$ in (4), the sign of $\rho_{3}$ cannot be determined ex ante without further assumptions. The first term in (7), $\delta_{Z}^{\prime} Z^{\prime} Z \beta_{Z}$, is assumed to be positive in the presence of private 
information, and the second term in (7), $\delta_{H}^{\prime} M^{\prime} M \beta_{H}$, is negative if $\beta_{H}$ and $\delta_{H}$ have opposite signs. But the signs of the remaining two terms in (7) cannot be determined without further assumptions. Therefore, it is possible that $\rho_{3}$ is not positive even if private information is present.

However, in the following discussion, we show that it is possible to solve this problem if we are willing to assume that the heterogeneity in the risk preferences can be captured by allowing each individual to be one of two types with an individual specific probability.

In particular, we assume that there are bold $(B)$ or timid $(T)$ individuals. $H$ takes two values, $H_{B}$ and $H_{T}{ }^{4}$ Given this assumption, we can rewrite equations in (1) for each type. For the timid type individuals $\left(H=H_{T}\right)$, we obtain:

$$
\begin{aligned}
N H= & 1\left(c_{\beta}+X \beta_{X}+Z \beta_{Z}+H_{T} \beta_{H}+u>0\right) \\
= & 1\left(c_{\beta}^{T}+X \beta_{X}+Z \beta_{Z}+u>0\right)=1\left(c_{\beta}^{T}+X \beta_{X}+u^{*}>0\right) \\
L T C I & =1\left(c_{\delta}+X \delta_{X}+Z \delta_{Z}+H_{T} \delta_{H}+v>0\right) \\
& =1\left(c_{\delta}^{T}+X \delta_{X}+Z \delta_{Z}+v>0\right)=1\left(c_{\delta}^{T}+X \beta_{X}+v^{*}>0\right)
\end{aligned}
$$

In both equations in (8), the effect of $H$ is absorbed into the constant terms, $c_{\beta}^{T}$ and $c_{\delta}^{T}$. Similarly, for the bold type individuals $\left(H=H_{B}\right)$, we obtain:

$$
\begin{aligned}
& N H=1\left(c_{\beta}^{B}+X \beta_{X}+u^{*}>0\right) \\
& L T C I=1\left(c_{\delta}^{B}+X \delta_{X}+v^{*}>0\right)
\end{aligned}
$$

Again, the constant terms $c_{\beta}^{B}$ and $c_{\delta}^{B}$ absorb the effect of $H$ while the error terms include the private information. The model predicts the relative magnitude of the constant terms. Everything else equal, a timid type individual would be more likely to purchase $L T C I$ but less likely to enter the nursing home than a bold type individual, i.e. $c_{\delta}^{T}>c_{\delta}^{B}$ and $c_{\beta}^{T}<c_{\beta}^{B}$. More importantly, the error terms $u^{*}$ and $v^{*}$ now only include the private information $\boldsymbol{Z}$, but not the individual heterogeneity. Therefore, the correlation between $u^{*}$ and $v^{*}$ reflects the presence of private information $\boldsymbol{Z}$. Imposing the two-type structure transforms the problem from one of

\footnotetext{
${ }^{4}$ More generally, both $H_{B}$ and $H_{T}$ can be random variables that are uncorrelated with $X$ and $Z$.
} 
identifying $H \beta_{H}$ and $H \delta_{H}$ in (1), to a problem of identifying $c_{\beta}^{T(B)}$ and $c_{\delta}^{T(B)}$, and - at least probabilistically - the type of an individual.

We need to jointly identify $c_{\beta}^{T}, c_{\delta}^{T}, c_{\beta}^{B}, c_{\delta}^{B}, \beta_{X}, \delta_{X}$, the probability of belonging to a certain type, and the correlations between the two error terms $u^{*}$ and $v^{*}$. Conditional on $X$ and $\boldsymbol{W}$, we observe four possible outcomes, $(N H=i, L T C I=j)$, for $i=0,1$ and $j=0,1$. The probability of a given outcome depends on the type of the individual:

$$
\begin{aligned}
& \operatorname{Pr}(N H=i, L T C I=j) \\
& =\operatorname{Pr}\left(N H=i, L T C I=j \mid H=H_{T}\right) \operatorname{Pr}\left(H=H_{T}\right) \\
& \quad+\operatorname{Pr}\left(N H=i, L T C I=j \mid H=H_{B}\right) \operatorname{Pr}\left(H=H_{B}\right)
\end{aligned}
$$

As described in equation (6), $H$ is determined by $\boldsymbol{W}$ and $\boldsymbol{M}$. We assume that the probability of being of a certain type varies with $\boldsymbol{W}$ :

$$
\operatorname{Pr}\left(H=H_{T} \mid W, M\right) \neq \operatorname{Pr}\left(H=H_{T}\right), \text { for some } \boldsymbol{W} \text { and } \boldsymbol{M} .
$$

If we assume that $\boldsymbol{W}$ is observed but $\boldsymbol{M}$ is not observed, it is not possible to consistently estimate the coefficient $\gamma$ in the equation below:

$$
\operatorname{Pr}\left(H=H_{T} \mid W, M\right)=\operatorname{Pr}(W \gamma+M+\varepsilon>0)
$$

Assuming that the unobserved $\boldsymbol{M}$ can be written as a linear function of $\boldsymbol{W}$ and an error term, i.e., $\boldsymbol{M}=\boldsymbol{W} \alpha+\tau$; equation (12) can be rewritten as

$$
\operatorname{Pr}\left(H=H_{T} \mid W\right)=\operatorname{Pr}(W \gamma+W \alpha+\tau+\varepsilon>0)=\operatorname{Pr}\left(W \gamma^{*}+\omega>0\right)
$$

where the random errors $\tau$ and $\varepsilon$ are normally distributed, and the parameter $\gamma^{*}$ is the sum of $\gamma$ and $\alpha$, scaled by a constant such that $\omega \sim N(0,1)$. In the linear model, $\gamma$ may be consistently estimated if $\boldsymbol{M}$ is uncorrelated with $\boldsymbol{W}$ (where $\alpha=0$ ). However, in the nonlinear setting here, $\gamma$ cannot be consistently estimated regardless of the correlation between $\boldsymbol{M}$ and $\boldsymbol{W}$.

The key identifying assumption is that - conditional on the type of an individual $-\boldsymbol{W}$ and $\boldsymbol{M}$ are not related to either the probability of entering a nursing home, or the probability to purchase long-term care insurance: 


$$
\operatorname{Pr}\left(N H=i, L T C I=j \mid H=H_{T}, W, M\right)=\operatorname{Pr}\left(N H=i, L T C I=j \mid H=H_{T}\right)
$$

Consequently, any association between $\boldsymbol{W}$ and $\boldsymbol{M}$ and the probability of entering a nursing home or purchasing insurance is solely driven by the association between $\boldsymbol{W}$ and $\boldsymbol{M}$ and the probability to belong to a certain type. In a separate paper, Henry, Kitamura and Salanié (2010) also propose this independence condition as one of the key assumptions of identifying the model.

Intuitively, this identification assumption is similar to the identification assumption of the instrumental variable model. $\boldsymbol{W}$ and $\boldsymbol{M}$ may be considered as the "instrumental variables" for the type variable $H$. They are assumed to be uncorrelated with $N H$ and $L T C I$ but correlated with H. More generally,

$$
\begin{aligned}
& \operatorname{Pr}(N H=i, L T C I=j \mid W, M) \\
& =\operatorname{Pr}\left(N H=i, L T C I=j \mid H=H_{T}\right) \operatorname{Pr}\left(H=H_{T} \mid W, M\right) \\
& \quad+\operatorname{Pr}\left(N H=i, L T C I=j \mid H=H_{B}\right) \operatorname{Pr}\left(H=H_{B} \mid W, M\right)
\end{aligned}
$$

Again, the relative contribution of $\boldsymbol{W}$ and $\boldsymbol{M}$ to the variation in $H$ does not affect $\operatorname{Pr}(N H=i, L T C I=j)$ conditional on the type of an individual. Rewriting (15) conditional on the observed variables $\boldsymbol{X}$ and $\boldsymbol{W}$ gives:

$$
\begin{aligned}
& \operatorname{Pr}(N H=i, L T C I=j \mid X, W) \\
& =\operatorname{Pr}\left(N H=i, L T C I=j \mid H=H_{T}, X\right) \operatorname{Pr}\left(H=H_{T} \mid W\right) \\
& \quad+\operatorname{Pr}\left(N H=i, L T C I=j \mid H=H_{B}, X\right) \operatorname{Pr}\left(H=H_{B} \mid W\right)
\end{aligned}
$$

All terms in (16) are defined in (8), (9), and (13). Therefore, one may construct a likelihood function to estimate such a model.

Lemma: If the probability of being a certain type varies with $\boldsymbol{W}$ (equation (12)), and - conditional on the type of an individual $-\boldsymbol{W}$ is not related to either the probability of entering a nursing home or the probability to purchase long-term care insurance (equation (14)), then estimating equations (8) and (9) together with either (12) or (13) produces consistent estimates of the parameters $c_{\beta}^{T}$, $c_{\delta}^{T}, c_{\beta}^{B}, c_{\delta}^{B}, \beta_{X}, \delta_{X}$, and the correlations between the two error terms $u^{*}$ and $v^{*}$ 
Equations (15) and (16) reveal that knowledge of $\boldsymbol{M}$ and estimation either (12) or (13) result in different estimates for the coefficient of $\boldsymbol{W}$, but the other coefficients of the model are not affected by the fact that $\boldsymbol{M}$ is not observed. The parameters of interest, $c_{\beta}^{T}, c_{\delta}^{T}, c_{\beta}^{B}, c_{\delta}^{B}, \beta_{X}$, $\delta_{X}$ and the correlation between $u^{*}$ and $v^{*}$ remain to be consistently estimated while coefficients of $\boldsymbol{W}$ will not. If we have more than one dimension of information in $\boldsymbol{W}$, we may only use a subset of $\boldsymbol{W}$ to estimate the model. This is very similar to the over identification test in the instrumental variable model where more than necessary instrumental variables are available. Similar discussions are also offered in Henry, Kitamura, and Salanié (2010).

In summary, the intuition of the method is very similar to the two-stage instrumental variable model. The consistency of the 2SLS estimates does not require the consistency of the first-stage regression. Similarly, the fact that we do not observe $\boldsymbol{M}$ does not create inconsistent estimates of the parameters of interest. Therefore, the advantage of the proposed method is that it only requires some (but not full) information about $H$ to identify the parameters of interest. Even the over identification test in the instrumental variable model has a corresponding test in the current model. In comparison, the method in the literature, as used by F\&MG, replaces the unobserved type variable $H$ by a set of proxies $\boldsymbol{W}$ in the $N H$ and $L T C I$ equations. It works only if $\boldsymbol{W}$ completely characterizes $H$. However, given how little we understand the unobserved heterogeneity $H$, this is unlikely to hold in practice.

\section{Data and Results}

We illustrate our estimation procedure by applying it to the data assembled by F\&MG. The data are based on the Asset and Health Dynamics (AHEAD) cohort of the Health and Retirement Study (HRS). This survey is designed to be representative of the non-institutionalized US population born in 1923 or earlier and their spouses. For more detailed information about sample and variables see F\&MG. 
It is possible to observe insurance status, nursing home utilization, and a number of demographic and health variables that make it possible to control for risk classification of individuals by insurers. F\&MG apply an actuarial model used by many insurers to calculate a variable that reflects the company prediction of nursing home use which is used to determine premiums. This company prediction captures the available public information, $\boldsymbol{X}$.

The data also contain information that is not used by insurers to set premiums. Based on a survey question, F\&MG construct a measure of private beliefs about the likelihood of moving into a nursing home. We use the private believes as a proxy for private information, $\boldsymbol{Z},-$ capturing some but not all of the private information of individuals. The self-reported probability of entering nursing home has been shown to be consistent on average with observed probabilities at the aggregate level, but has serious reporting errors at individual level (see, for example, Hurd and McGarry 2002; Gan, Hurd and McFadden 2005), suggesting that the measure can best serve a noisy proxy to the private information.

The data also contain information about wealth and proxies for risk attitudes. The proxies for risk attitudes are self-reported seat belt usage and whether individuals undertook preventative healthcare measures, such as flu shots or cancer screenings.

Table 1 displays the descriptive statistics. The sample contains 5,119 individuals. $11 \%$ of them have long-term care insurance in 1995 and 16\% enter a nursing home at some point from 1995-2000. However, to be comparable across various specifications, we limit our sample to individuals without missing information for any utilized variable. The working sample size consists of 5,000 observations.

We first estimate model (2) for only one type of agent to provide a baseline for our further analysis. In all specifications, we control in both equations for the public information available to the insurance company, $X$, summarized by the company predictor variable. 
The estimates reported here are similar to those reported by F\&MG. ${ }^{5}$ In the first column in Table 2, we confirm that the company prediction has a positive effect on the probability of entering a nursing home. The estimated coefficient for the company predictor $\left(\beta_{X}\right)$ is 1.805 (0.090). ${ }^{6}$ However, the insurance company predictor reduces the probability of purchasing insurance. The estimated coefficient $\left(\delta_{X}\right)$ is $-0.694(0.123)$, corresponding a marginal effect of -0.129. We obtain a negative (not significantly different from zero) estimate at $-0.036(0.041)$ for the correlation between the two error terms. In other words the correlation test does not provide evidence for the existence of asymmetric information.

Next, in the second column in Table 2, we add the proxies for private information, individual predictions to enter nursing homes, $Z$, to the two equations. The coefficient for this variable is positive in both equations, implying that indeed private information is present.

The third column in Table 2 displays the results for the model after we added proxies for the risk attitudes (types) of individuals, $\boldsymbol{W}$, but without the individual prediction. These proxy variables for risk attitudes are dummy variables for "preventative health measures taken", seat belt usage and for the $4^{\text {th }}, 3^{\text {rd }}$, and $2^{\text {nd }}$ wealth quartile. We confirm that the coefficients for the variables in $\boldsymbol{W}$ have opposite signs in the two equations. F\&MG argue that different signs in $\boldsymbol{W}$ in two equations actually indicate the heterogeneity in tastes.

Now, we estimate the model with two types of individuals. We jointly estimate (13), (8), and (9). Let $H=1$ be the timid type and $H=0$ be the bold type. $\boldsymbol{W}$ consists of seat belt usage, preventative healthcare measures, and wealth quartiles.

We restrict the coefficients $\beta_{X}, \delta_{X}$ and the correlation $\rho$ to be identical for the two types, but allow the constant terms differ. Column 1 in Table 3 displays the results (the corresponding marginal effects are shown in Table A2). The top panel illustrates the effect of factors predicting

\footnotetext{
${ }^{5}$ To make our estimates comparable to each other our specification differs slightly from those in F\&MG. When using the exact specifications as that of F\&MG, we obtain the same results.

${ }^{6}$ This corresponds to a marginal effect of 0.40 if other variables are evaluated at their means (See table A1).
} 
the type of an individual. Overall, $28 \%$ of individuals belong to the timid type. Individuals of the timid type are characterized by a higher incidence of preventative activities and seat belt use; they also tend to be wealthier. A person who takes preventative activities has a 11 percentage points higher probability to be the timid type. Always wearing seat belt increases this probability by 13 percentage points. Finally, compared with individuals in the fourth (lowest) wealth quartile, having a wealth level in the top quartile (first quartile) increases the probability of belonging to the timid type by 28 percentages points, for individuals in the second quartile the increase is 20 percentage points, and for individuals in the third quartile it is 12 percentage points.

People who belong to different types exhibit clear differences in their behavior. As predicted by the model, we find that a timid-type individual is more likely to purchase the LTCI but less likely to enter a nursing home. For a timid-type person, the average likelihood of being insured is 0.41 while the chance to use nursing home is just 0.03 . One the contrary, for the bold-type person, the average probability of purchasing long-term care insurance is less than 0.01 ; the odds of entering nursing home are 0.19 . The lower panel of Table 3 displays the relationship between individual characteristics and insurance purchases and nursing home usage.

As predicted in the previous subsection, the proposed model has clear predictions in terms of the relative magnitude of the constant terms. For the LTCI model, the estimated constant $c_{\delta}^{T}$ for the timid type is -0.269 (0.188), significantly larger than the estimated constant $c_{\delta}^{B}$ for the bold type at $-2.312(0.237)$. A one-sided $Z$-test rejects the null hypothesis that $\hat{c}_{\delta}^{T} \leq \hat{c}_{\delta}^{B}$ $(p$-value $=0.000) . \quad$ For the $N H$ model, the estimated constant for the timid type $c_{\beta}^{T}$ is -2.288 (0.215), statistically smaller than the estimated constant for the bold type $c_{\beta}^{B}$ at $-1.269(0.061)$, $p$-value $=0.000 . \quad$ Both test results are consistent with the predictions of the model. In terms of probabilities of purchasing $L T C I$ and entering nursing homes, the timid type would be 40 percentage points more likely to purchase $L T C I$ but 16 percentage points less likely to enter into nursing homes. 
Most importantly, by separating individuals into two types, we are able to obtain clear evidence of private information. The estimated correlation between the error terms in the $\mathrm{NH}$ model and the LTCI model is positive and statistically significant at $0.621(0.271)$. It is important to note that this is achieved without using any data on private information.

The second set of estimates in Table 3 includes one dimension of private information, the individual prediction of entering nursing homes, in both the LTCI equation and the NH equation. As in the case of one type model in Table 2, the coefficient of this variable is positive in both LTCI and $\mathrm{NH}$ equations, showing the importance of such private information in determining both the decisions to buy $L T C I$ and to enter nursing homes. Adding the proxy for private information reduces the correlation between the two error terms to $0.566(0.209)$, although it remains positive and statistically significant. This result reveals that (a) the individual prediction of entering nursing home as elicited in the survey may only characterize a small portion of the private information; and (b) adding more and more private information may eventually lead to zero correlation, as predicted by the model.

Unlike the one-type model, our two-type model can detect the existence of the private information even in the absence of observable data on private information. If some data on private information is observed, our model can indicate to what extent additional unobserved private information influences the decision to purchase insurance.

As emphasized in the previous subsection, similar to the over identification test in the instrumental variable model, one implication of our model is that even a partial set of $\boldsymbol{W}$ may produce consistent estimates of the key parameters of interest. Therefore, as a further test of the model, we vary the choice of variables in determining types, $\boldsymbol{W}$. In our current setting, the set $\boldsymbol{W}$ consists of wealth quartiles and preventive care, always wearing seat belts. Wealth is a natural candidate for W. As pointed out by F\&MG Medicaid offers a better substitute for private insurance for low wealth individuals and is therefore correlated with the risk preferences of individuals. It is plausible that the variables preventative care and always wearing seat belt are 
associated with risk preferences, as well. However, it might be argued that these variables are correlated with the likelihood of eventual nursing home use, violating our identifying assumption.

In the first two columns in Table 4, we do not include any variables in $\boldsymbol{W}$. In column (1) we only include the company predictor, $\boldsymbol{X}$, while column (2) includes individual private information on entering nursing homes, $\boldsymbol{Z}$. The insurance company predictor remains positive in the $\mathrm{NH}$ equation and negative in the $L T C I$ equation. More importantly, the constant in both equations satisfy the predictions of our two-type model. However, the correlation between the error terms in both $\mathrm{NH}$ equation and the $L T C I$ equation is no longer significant. This result is expected since there is no information to economically distinguish the two types of consumers and the type is purely identified by functional form. Therefore, one of our two identification assumptions - the probabilities of purchasing insurance and nursing home use have to vary with $\boldsymbol{W}-$ is violated.

The second column includes private information on entering nursing home. The coefficient estimates for the private information variable are positive and significant in both $\mathrm{NH}$ and LTCI equations. Again, the correlation between the error terms is not statistically significant.

The third and fourth column in Table 4 show the results when the wealth quartiles information is used. Our model shows that parameter estimates in both $N H$ and LTCI equations should be similar to the corresponding parameter estimates in Table 3 when all available information in $\boldsymbol{W}$ is used. Both sets of estimates are indeed similar to each other. For example, in the column (3) in Table 4, the coefficient estimate for the insurance company predictor is 1.833 (0.101) in the $\mathrm{NH}$ equation. The corresponding coefficient estimate in Table 3 is $1.828(0.104)$. The coefficient estimate for constant term in NH (timid type) equation in Table 4 is $-2.203(0.237)$ while the corresponding coefficient estimate in Table 3 is $-2.288(0.215)$. The correlation between the error terms in the $N H$ model and the $L T C I$ model is positive and statistically significant. It is $0.595(0.266)$ without any direct information on private information and - as expected - drops to 0.472(0.275) after adding private information in column (4). 
The fifth and sixth column in Table 4 list results using variables of preventive activities and seat belt usage with the fifth column only has the company predictor while the sixth column includes both the company predictor and private predictor. The coefficient estimates in both $\mathrm{NH}$ equation and LTCI equation have the expected signs and are statistically significant. The estimates of the constants are consistent with the predictions of our model However, the correlation between the error terms in the $\mathrm{NH}$ model and the LTCI model is no longer positive. This highlights the importance of the validity of the identifying assumptions for the elements of $\boldsymbol{W}$. As in a standard instrumental variable approach, a violation of the identifying assumptions will lead to biased results.

Table 5 presents a formal test. The test compares the estimates of the parameters of interest in the $\mathrm{NH}$ and $\mathrm{LTCI}$ equations presented in Table 3 and Table 4. Our theoretical analysis suggests that having a partial set of $\boldsymbol{W}$ may affect the estimates for the coefficient estimates for $\boldsymbol{W}$ in the type equation but not the coefficients in the $N H$ and $L T C I$ equations. The first set of columns in the table compares estimates from the full model with the wealth-quartile-only model, while the second set of columns compares estimates from the full model with the set of cautious activities (preventive activity and seat belt use). The first row compares the parameter estimates in both the NH and LTCI equations, while the second row compares the parameter estimates in the type-equations. As expected, the estimates in the $N H$ and $L T C I$ equations in two models are not statistically different with each other. Interestingly, the estimates in the type-determination equation from these two sets of estimates are not different from each other, either. One potential reason for this may be due to fact that the omitted sets of $\boldsymbol{W}$ (the preventive activity and seat belt use) are independent on the wealth quartiles.

Finally, the second panel in table 5 compares the full model with the model with only prevention and seat belt usage variables as $\boldsymbol{W}$. The $\chi^{2}$ test statistics are very large, indicating that estimates from the two models are statistically different from each other for both the coefficients in the $L T C I$ and $N H$ equations and for the type equations. One possible reason is that 
prevention and seat belt use variables may not be sufficient to identify the model. The true reason remains to be understood.

\section{Conclusions}

Identifying private information in the insurance markets is important for empirically testing the economic theories of moral hazard and adverse selection. It is also useful to improve efficiency of the insurance market. This paper proposes and estimates a new method to identify private information in the presence of heterogeneity consumer types. We illustrate this method for an insurance market where direct evidence for private information is available. We are able to detect the presence of asymmetric information without using this direct evidence.

In particular, this paper makes three contributions to the literature. First, when only a partial set of information is available to characterize the individual heterogeneity, this study investigates the reason for the failure of current methods which intend to test a positive relationship between the demand of insurance and the usage of the service and identify the private information. Second, based on the discussion, this paper proposes a new method to identify private information with individuals' risk heterogeneity only using a partial set of information to characterize such risk heterogeneity. This method assumes that individuals' risk heterogeneity can be grouped into two unobserved categories. Third, although private information is known to be present in the long term care market, it cannot be detected by the existing method. However, it can be detected by the proposed method.

The identification of this method is similar to that of the instrumental variable model. It requires the variables characterizing risk heterogeneity are - conditional on the type of an individual - uncorrelated with decisions to purchase insurance and to use the service covered by the insurance. The procedure described here is a tool that can be used to detect the presence of private information in the insurance markets with heterogeneous risk preferences even when the direct evidence of private information is not available. 


\section{References}

Cawley, John and Philipson, Tomas (1999). "An empirical examination of information barriers to trade in insurance." American Economic Review, 1999, 89 (4), pp.827-846.

Chiappori, Pierre-Andre (2000). "Econometric models of insurance under asymmetric Information.” In Georges Dionne, ed. Handbook of Insurance Economics. London: Kluwer.

Chiappori, Pierre-Andre and Salanié, Bernard (2000). "Testing for asymmetric information in insurance markets.” Journal of Political Economy, 2000, 108 (1), pp. 56-78.

Chiappori, Pierre-Andre, Jullien, Bruno, Salanié, Bernard and Salanié, Francois (2006).

"Asymmetric information in insurance: general testable implications." Rand Journal of Economics. Vol. 37, No. 4 (Winter, 2006), pp. 783-798

Cohen, Alma (2005). “Asymmetric information and learning: evidence from the automobile insurance." The Review of Economics and Statistics. May 2005 82(2): 197-207.

de Meza, David and Webb, David C. (2001) "Advantageous selection in insurance markets." Rand Journal of Economics, Summer 200132 (2), pp. 249-262

Finkelstein, Amy and McGarry, Kathleen (2006). "Multiple dimensions of private information: evidence from the long-term care insurance market." American Economic Review, Vol. 96 No.4, Page 938-958.

Finkelstein, Amy and Poterba, James (2002). "Selection effects in the market for individual annuities: new evidence from the United Kingdom.” Economic Journal, 2002, 112 (476), pp. 28-50.

Fang, Hanming, Keane, Michael P. and Silverman, Dan (2008). "Sources of advantageous selection: evidence from the Medigap insurance market." Journal of Political Economy. Volume 116, Issue 2, Page 303-350, Apr 2008

He, Daifeng (2009). “The life insurance market: asymmetric information revisited." Journal of Public Economics.

Henry, Marc, Kitamura, Yuichi, and Salanié, Bernard (2010) "Identifying Finite Mixtures in Econometric Models" Cowles Foundation Discussion Paper No. 1767.

Hurd, Michael D. and McGarry, Kathleen (2002). "The Predictive validity of subjective probabilities of survival." Economic Journal, 2002, 112(482), pp. 966-85

Gan, Li, Hurd, Michael D. and McFadden, Daniel (2005). "Individual subjective survival curves," in David Wise, ed., Analysis in economics of aging. Chicago: University of Chicago Press, 2005, pp. 377-411. 
Gan, Li and Mosquera, Roberto (2008). "An empirical study of the credit market with unobserved consumer types." NBER WPS \#13873.

Keane, Michael P. and Wolpin, Kenneth I. (1997) “The career decisions of young men.” Journal of Political Economy, Vol. 105, No. 3 (Jun., 1997), pp. 473-522

Knittel, Christopher and Stango, Victor (2003). "Price Ceilings as Focal Points for Tacit Collusion: Evidence from Credit Cards.” American Economic Review, Vol. 93, No. 5 (Dec., 2003), pp. 1703-1729

Lee, Lung-Fei and Porter, Robert (1984). "Switching regression models with imperfect sample separation information: application on cartel stability." Econometrica, Vol. 52, No. 2 (Mar., 1984), pp. 391-418

Rothschild, Michael and Stiglitz, Joseph (1976) "Equilibrium in competitive insurance markets: an essay on the economics of imperfect information." Quarterly Journal of Economics, 1976, 90 (4) pp. 629-649.

Smart, Michael (2000) "Competitive insurance markets with two unobservables." International Economic Review, 2000, 41(1) pp. 153-169. 
Table 1: Descriptive Statistics

\begin{tabular}{lrrrr}
\hline \hline Variable & Mean & \multicolumn{1}{l}{ sd } & Min & Max \\
\hline & & & & \\
Nursing Home Use & 0.163 & 0.369 & 0 & 1 \\
Long Term Care Insurance & 0.108 & 0.311 & 0 & 1 \\
Insurance company prediction & 0.218 & 0.231 & 0.006 & 1 \\
Individual prediction & 0.177 & 0.248 & 0 & 1 \\
Preventive health activity & 0.659 & 0.304 & 0 & 1 \\
Always wear seat belt & 0.768 & 0.422 & 0 & 1 \\
Top quartile of wealth & 0.285 & 0.451 & 0 & 1 \\
$3^{\text {rd }}$ Wealth quartile & 0.270 & 0.444 & 0 & 1 \\
$2^{\text {nd }}$ Wealth quartile & 0.243 & 0.429 & 0 & 1 \\
\hline \hline
\end{tabular}

Note: The sample consists of the elderly aged 78 on average in 1995 who reported long-term care insurance status and nursing home use from 1995 to 2000 from the Asset and Health Dynamics (AHEAD) cohort of the Health and Retirement Study (5,119 observations). 
Table 2: One type Bivariate Probit Model

\begin{tabular}{|c|c|c|c|c|c|}
\hline & & $\begin{array}{c}\text { Company } \\
\text { prediction } \\
(1) \\
\end{array}$ & $\begin{array}{c}\text { Company and } \\
\text { individual } \\
\text { prediction } \\
\text { (2) }\end{array}$ & $\begin{array}{c}\text { Company } \\
\text { prediction, } \\
\text { prevention } \\
\text { and wealth } \\
\text { quartiles } \\
\text { (3) } \\
\end{array}$ & $\begin{array}{l}\text { Company and } \\
\text { individual } \\
\text { prediction, } \\
\text { prevention and } \\
\text { wealth quartiles } \\
\text { (4) } \\
\end{array}$ \\
\hline \multirow[t]{16}{*}{ NH } & Insurance company prediction & $1.805 * * *$ & $1.786^{* * *}$ & $1.708 * * *$ & $1.683 * * *$ \\
\hline & & $(0.090)$ & $(0.091)$ & $(0.093)$ & $(0.094)$ \\
\hline & Individual prediction & & $0.186 * *$ & & $0.208 * *$ \\
\hline & & & $(0.092)$ & & $(0.092)$ \\
\hline & Preventive health activity & & & $-0.176^{* *}$ & $-0.187 * *$ \\
\hline & & & & $(0.081)$ & $(0.081)$ \\
\hline & Always wear seat belt & & & $-0.114^{* *}$ & $-0.116 * *$ \\
\hline & & & & $(0.056)$ & $(0.056)$ \\
\hline & Top quartile of assets & & & $-0.125 *$ & $-0.124 *$ \\
\hline & & & & $(0.072)$ & $(0.072)$ \\
\hline & $3^{\text {rd }}$ Wealth quartile & & & -0.070 & -0.071 \\
\hline & & & & $(0.071)$ & $(0.071)$ \\
\hline & $2^{\text {nd }}$ Wealth quartile & & & 0.026 & 0.026 \\
\hline & & & & $(0.071)$ & $(0.071)$ \\
\hline & Constant & $-1.459 * * *$ & $-1.490 * * *$ & $-1.188 * * *$ & $-1.213 * * *$ \\
\hline & & $(0.034)$ & $(0.037)$ & $(0.081)$ & $(0.082)$ \\
\hline \multirow[t]{20}{*}{ LTCI } & Insurance company prediction & $-0.694 * * *$ & $-0.781 * * *$ & $-0.431 * * *$ & $-0.522 * * *$ \\
\hline & & $(0.123)$ & $(0.126)$ & $(0.128)$ & $(0.131)$ \\
\hline & Individual prediction & & $0.547 * * *$ & & $0.538 * * *$ \\
\hline & & & $(0.094)$ & & $(0.097)$ \\
\hline & Preventive health activity & & & $0.162 *$ & 0.134 \\
\hline & & & & $(0.095)$ & $(0.096)$ \\
\hline & Always wear seat belt & & & $0.234 * * *$ & $0.232 * * *$ \\
\hline & & & & $(0.068)$ & $(0.068)$ \\
\hline & Top quartile of assets & & & $0.592 * * *$ & $0.596^{* * *}$ \\
\hline & & & & $(0.088)$ & $(0.089)$ \\
\hline & $3^{\text {rd }}$ Wealth quartile & & & $0.424 * * *$ & $0.421 * * *$ \\
\hline & & & & $(0.090)$ & $(0.091)$ \\
\hline & $2^{\text {nd }}$ Wealth quartile & & & $0.275^{* * *}$ & $0.272 * * *$ \\
\hline & & & & $(0.093)$ & $(0.094)$ \\
\hline & Constant & $-1.092 * * *$ & $-1.184 * * *$ & $-1.836^{* * *}$ & $-1.904 * * *$ \\
\hline & & $(0.034)$ & $(0.038)$ & $(0.112)$ & $(0.116)$ \\
\hline & Correlation of two error terms $\rho$ & -0.036 & -0.044 & -0.015 & -0.023 \\
\hline & & $(0.041)$ & $(0.040)$ & $(0.041)$ & $(0.041)$ \\
\hline & Number of observations & 5,000 & 5,000 & 5,000 & 5,000 \\
\hline & Log-Likelihood & -3713.25 & -3698.15 & -3657.14 & -3642.50 \\
\hline
\end{tabular}


Table 3: Two-type Model

\begin{tabular}{|c|c|c|c|c|}
\hline & \multicolumn{2}{|c|}{$\begin{array}{c}\text { Company predictor } \\
\text { only } \\
\text { (1) }\end{array}$} & \multicolumn{2}{|c|}{$\begin{array}{c}\text { Company and Individual } \\
\text { predictors } \\
\text { (2) } \\
\end{array}$} \\
\hline \multicolumn{5}{|l|}{ Type (timid type $=1$ ) } \\
\hline Preventive health activity & \multicolumn{2}{|c|}{$\begin{array}{c}0.308^{* *} \\
(0.145)\end{array}$} & \multicolumn{2}{|c|}{$\begin{array}{c}0.273^{*} \\
(0.151)\end{array}$} \\
\hline Always wear seat belt & \multicolumn{2}{|c|}{$\begin{array}{c}0.382 * * * \\
(0.104)\end{array}$} & \multicolumn{2}{|c|}{$\begin{array}{c}0.393 * * * \\
(0.104)\end{array}$} \\
\hline Top quartile of assets & \multicolumn{2}{|c|}{$\begin{array}{c}0.852 * * * \\
(0.132)\end{array}$} & \multicolumn{2}{|c|}{$\begin{array}{c}0.876^{* * *} * \\
(0.133)\end{array}$} \\
\hline $3^{\text {rd }}$ Wealth quartile & \multicolumn{2}{|c|}{$\begin{array}{c}0.593 * * * \\
(0.133)\end{array}$} & \multicolumn{2}{|c|}{$\begin{array}{l}0.605 * * * \\
(0.133)\end{array}$} \\
\hline $2^{\text {nd }}$ Wealth quartile & \multicolumn{2}{|c|}{$\begin{array}{c}0.349 * * * \\
(0.133)\end{array}$} & \multicolumn{2}{|c|}{$\begin{array}{c}0.355^{* * *} \\
(0.134)\end{array}$} \\
\hline \multirow[t]{2}{*}{ Constant } & \multicolumn{2}{|c|}{$\begin{array}{c}-1.574 * * * \\
(0.185) \\
\end{array}$} & \multicolumn{2}{|c|}{$\begin{array}{c}-1.546^{* * *} \\
(0.183) \\
\end{array}$} \\
\hline & Timid type & Bold type & Timid type & Bold type \\
\hline \multicolumn{5}{|l|}{$\mathrm{NH}$} \\
\hline Insurance company prediction & $\begin{array}{c}1.828 * * * \\
(0.104)\end{array}$ & $\begin{array}{c}1.828^{* * *} \\
(0.104)\end{array}$ & $\begin{array}{c}1.798^{* * *} \\
(0.103)\end{array}$ & $\begin{array}{c}1.798 * * * \\
(0.103)\end{array}$ \\
\hline Individual prediction & & & $\begin{array}{c}0.211^{* *} \\
(0.098)\end{array}$ & $\begin{array}{c}0.211 * * \\
(0.098)\end{array}$ \\
\hline Constant & $\begin{array}{c}-2.288 * * * \\
(0.215)\end{array}$ & $\begin{array}{c}-1.269 * * * \\
(0.061)\end{array}$ & $\begin{array}{c}-2.254 * * * \\
(0.239)\end{array}$ & $\begin{array}{c}-1.303^{* * *} \\
(0.063)\end{array}$ \\
\hline \multicolumn{5}{|l|}{ LTCI } \\
\hline Insurance company prediction & $\begin{array}{c}-0.628 * * * \\
(0.184)\end{array}$ & $\begin{array}{c}-0.628 * * * \\
(0.184)\end{array}$ & $\begin{array}{c}-0.751 * * * \\
(0.190)\end{array}$ & $\begin{array}{c}-0.751 * * * \\
(0.190)\end{array}$ \\
\hline Individual prediction & & & $\begin{array}{c}0.824 * * * \\
(0.197)\end{array}$ & $\begin{array}{c}0.824 * * * \\
(0.197)\end{array}$ \\
\hline Constant & $\begin{array}{l}-\mathbf{0 . 2 6 9} \\
(0.188)\end{array}$ & $\begin{array}{c}-2.312^{* * *} \\
(0.237)\end{array}$ & $\begin{array}{c}-\mathbf{0 . 4 2 6} \\
(0.166)\end{array}$ & $\begin{array}{c}-2.498 * * * \\
(0.331)\end{array}$ \\
\hline$\rho$ & $\begin{array}{r}0.621 * * \\
(0.271)\end{array}$ & & $\begin{array}{r}0.566^{* * * *} \\
(0.209)\end{array}$ & \\
\hline Loglikelihood & -3658.49 & & -3643.55 & \\
\hline Number of Obs & 5,000 & & 5,000 & \\
\hline
\end{tabular}


Table 4: Two-type Model: Robustness check

\begin{tabular}{|c|c|c|c|c|c|c|}
\hline & \multicolumn{2}{|c|}{ Constant } & \multicolumn{2}{|c|}{ Wealth quartiles } & \multicolumn{2}{|c|}{$\begin{array}{l}\text { Preventive activity and Seat } \\
\text { belt }\end{array}$} \\
\hline & $(1)$ & $(2)$ & (3) & (4) & (5) & (6) \\
\hline \multicolumn{7}{|l|}{$\operatorname{Pr}($ timid type $=1)$} \\
\hline Preventive health activity & & & & & $\begin{array}{l}3.379 * * \\
(1.676)\end{array}$ & $\begin{array}{l}3.306 * * \\
(1.636)\end{array}$ \\
\hline Always wear seat belt & & & & & $\begin{array}{c}2.892 * * \\
(1.331)\end{array}$ & $\begin{array}{c}2.936^{* *} \\
(1.390)\end{array}$ \\
\hline Top quartile of wealth & & & $\begin{array}{l}0.913 * * * \\
(0.136)\end{array}$ & $\begin{array}{l}0.944 * * * \\
(0.140)\end{array}$ & & \\
\hline $3^{\text {rd }}$ Wealth quartile & & & $\begin{array}{l}0.643 * * * \\
(0.129)\end{array}$ & $\begin{array}{c}0.657 * * * \\
(0.132)\end{array}$ & & \\
\hline $2^{\text {nd }}$ Wealth quartile & & & $\begin{array}{c}0.387 * * * \\
(0.124)\end{array}$ & $\begin{array}{c}0.391 * * * \\
(0.126)\end{array}$ & & \\
\hline Constant & $\begin{array}{c}0.459 * * * \\
(0.052)\end{array}$ & $\begin{array}{c}0.463 * * * \\
(0.051)\end{array}$ & $\begin{array}{c}-1.234 * * * \\
(0.189)\end{array}$ & $\begin{array}{c}-1.188^{* * * *} \\
(0.178)\end{array}$ & $\begin{array}{c}-4.316^{* *} \\
(1.871)\end{array}$ & $\begin{array}{c}-4.291 * * \\
(1.898)\end{array}$ \\
\hline \multicolumn{7}{|l|}{ NH (timid type) } \\
\hline $\begin{array}{c}\text { Insurance company } \\
\text { prediction }\end{array}$ & $\begin{array}{c}8.763 * * * \\
(1.462)\end{array}$ & $\begin{array}{c}8.702 * * * \\
(1.409)\end{array}$ & $\begin{array}{c}1.833 * * * \\
(0.101)\end{array}$ & $\begin{array}{c}1.799 * * * \\
(0.105)\end{array}$ & $\begin{array}{c}1.756^{* * *} \\
(0.091)\end{array}$ & $\begin{array}{c}1.733 * * * \\
(0.092)\end{array}$ \\
\hline Individual prediction & & $\begin{array}{l}0.377^{*} \\
(0.209)\end{array}$ & & $\begin{array}{c}0.199 * * \\
(0.097)\end{array}$ & & $\begin{array}{c}0.206 * * \\
(0.092)\end{array}$ \\
\hline Constant $c_{\beta}^{T}$ & $\begin{array}{c}\mathbf{- 8 . 4 6 3 * * *} \\
(1.301)\end{array}$ & $\begin{array}{c}\mathbf{- 8 . 4 6 3} * * * \\
(1.255)\end{array}$ & $\begin{array}{c}-2.203 * * * \\
(0.237)\end{array}$ & $\begin{array}{c}-2.120 * * * \\
(0.396)\end{array}$ & $\begin{array}{c}-1.544 * * * \\
(0.057)\end{array}$ & $\begin{array}{c}-1.581 * * * \\
(0.061)\end{array}$ \\
\hline \multicolumn{7}{|l|}{ NH (bold type) } \\
\hline $\begin{array}{c}\text { Insurance company } \\
\text { prediction }\end{array}$ & $\begin{array}{c}8.763 * * * \\
(1.462)\end{array}$ & $\begin{array}{c}8.702 * * * \\
(1.409)\end{array}$ & $\begin{array}{c}1.833 * * * \\
(0.101)\end{array}$ & $\begin{array}{c}1.799 * * * \\
(0.105)\end{array}$ & $\begin{array}{c}1.756^{* * *} \\
(0.091)\end{array}$ & $\begin{array}{c}1.733 * * * \\
(0.092)\end{array}$ \\
\hline Individual prediction & & $\begin{array}{l}0.377^{*} \\
(0.209)\end{array}$ & & $\begin{array}{c}0.199 * * \\
(0.097)\end{array}$ & & $\begin{array}{c}0.206^{* *} \\
(0.092)\end{array}$ \\
\hline Constant $c_{\beta}^{B}$ & $\begin{array}{c}-1.370 * * * \\
(0.123)\end{array}$ & $\begin{array}{c}-1.424 * * * \\
(0.129)\end{array}$ & $\begin{array}{c}-\mathbf{1 . 3 1 3} \mathbf{3}^{* * *} \\
(0.061)\end{array}$ & $\begin{array}{c}-1.343^{* * *} \\
(0.066)\end{array}$ & $\begin{array}{c}-1.329 * * * \\
(0.053)\end{array}$ & $\begin{array}{c}-1.357^{* * *} \\
(0.055)\end{array}$ \\
\hline \multicolumn{7}{|l|}{ LTCI (timid type) } \\
\hline $\begin{array}{c}\text { Insurance company } \\
\text { prediction }\end{array}$ & $\begin{array}{c}-0.696^{* * *} \\
(0.124)\end{array}$ & $\begin{array}{c}-0.783^{* * * *} \\
(0.127)\end{array}$ & $\begin{array}{c}-0.763 * * * \\
(0.213)\end{array}$ & $\begin{array}{c}-0.873 * * * \\
(0.215)\end{array}$ & $\begin{array}{c}-0.593 * * * \\
(0.125)\end{array}$ & $\begin{array}{c}-0.684 * * * \\
(0.128)\end{array}$ \\
\hline Individual prediction & & $\begin{array}{c}0.547 * * * \\
(0.094)\end{array}$ & & $\begin{array}{c}0.923 * * * \\
(0.275)\end{array}$ & & $\begin{array}{c}0.525 * * * \\
(0.096)\end{array}$ \\
\hline Constant $c_{\delta}^{T}$ & $\begin{array}{c}-1.100 * * * \\
(0.057)\end{array}$ & $\begin{array}{c}-\mathbf{1 . 1 8 5} * * * \\
(0.058)\end{array}$ & $\begin{array}{l}\mathbf{- 0 . 0 8 9} \\
(0.273)\end{array}$ & $\begin{array}{l}-\mathbf{0 . 3 0 9} \\
(0.209)\end{array}$ & $\begin{array}{c}-\mathbf{0 . 9 6 3} * * * \\
(0.059)\end{array}$ & $\begin{array}{c}-1.057 * * * \\
(0.059)\end{array}$ \\
\hline LTCI (bold type) & & & & & & \\
\hline $\begin{array}{l}\text { Insurance company } \\
\text { prediction }\end{array}$ & $\begin{array}{c}-0.696^{* * *} \\
(0.124)\end{array}$ & $\begin{array}{c}-0.783 * * * \\
(0.127)\end{array}$ & $\begin{array}{c}-0.763 * * * \\
(0.213)\end{array}$ & $\begin{array}{c}-0.873 * * * \\
(0.215)\end{array}$ & $\begin{array}{c}-0.593 * * * \\
(0.125)\end{array}$ & $\begin{array}{c}-0.684 * * * \\
(0.128)\end{array}$ \\
\hline Individual prediction & & $\begin{array}{c}0.547 * * * \\
(0.094)\end{array}$ & & $\begin{array}{c}0.923 * * * \\
(0.275)\end{array}$ & & $\begin{array}{c}0.525 * * * \\
(0.096)\end{array}$ \\
\hline Constant $c_{\delta}^{B}$ & $\begin{array}{c}\mathbf{- 1 . 0 7 4 * * *} \\
(0.098)\end{array}$ & $\begin{array}{c}-1.179 * * * \\
(0.100)\end{array}$ & $\begin{array}{c}-2.317 * * * \\
(0.256)\end{array}$ & $\begin{array}{c}-2.564^{* * *} \\
(0.591)\end{array}$ & $\begin{array}{c}-1.387 * * * \\
(0.080)\end{array}$ & $\begin{array}{c}-1.464^{* * *} \\
(0.082)\end{array}$ \\
\hline$\rho$ & $\begin{array}{c}\mathbf{- 0 . 0 9 7} \\
(0.114)\end{array}$ & $\begin{array}{l}\mathbf{- 0 . 0 9 6} \\
(0.113)\end{array}$ & $\begin{array}{c}\text { 0.595** } \\
(0.266)\end{array}$ & $\begin{array}{c}\mathbf{0 . 4 7 2} * \\
(0.275)\end{array}$ & $\begin{array}{c}-\mathbf{0 . 0 1 7} \\
(0.042)\end{array}$ & $\begin{array}{c}\mathbf{- 0 . 0 2 5} \\
(0.042)\end{array}$ \\
\hline Loglikelihood & -3677.7008 & -3663.555 & -3673.8107 & -3658.1565 & -3683.5369 & -3669.3261 \\
\hline Number of Obs & 5,000 & 5,000 & 5,000 & 5,000 & 5,000 & 5,000 \\
\hline
\end{tabular}


Table 5: Hausman test: Baseline model vs Robust check

\begin{tabular}{lcccccc}
\hline & \multicolumn{2}{c}{ Baseline model $v s$ wealth only } & & \multicolumn{2}{c}{$\begin{array}{c}\text { Baseline model } v s \\
\text { Preventive activity \& Seat belt only } \\
\end{array}$} & \multicolumn{2}{c}{$(1)$} & & & \multicolumn{2}{c}{$(2)$} \\
\cline { 2 - 3 } \cline { 6 - 7 } & $\begin{array}{c}\text { Company } \\
\text { prediction }\end{array}$ & $\begin{array}{c}\text { Both } \\
\text { predictions }\end{array}$ & & $\begin{array}{c}\text { Company } \\
\text { prediction }\end{array}$ & $\begin{array}{c}\text { Both } \\
\text { predictions }\end{array}$ \\
\hline NH and $L T C I$ equations & 1.068 & 1.033 & & $38.302^{* * *}$ & $34.243^{* * *}$ \\
& $(0.998)$ & $(0.999)$ & & $(0.000)$ & $(0.000)$ \\
\hline Type equation & 1.824 & 2.162 & & $9.185^{* *}$ & $8.999^{* *}$ \\
& $(0.768)$ & $(0.706)$ & & $(0.027)$ & $(0.029)$ \\
\hline
\end{tabular}

Notes: Table reports the Hausman test statistics and p-values in the parenthesis. 
Table A1: One type Bivariate Probit Model: Marginal effects at average

\begin{tabular}{|c|c|c|c|c|}
\hline & $\begin{array}{c}\text { Company } \\
\text { prediction } \\
(1) \\
\end{array}$ & $\begin{array}{l}\text { Company and } \\
\text { Individual } \\
\text { prediction } \\
(2)\end{array}$ & $\begin{array}{l}\text { Company } \\
\text { prediction and } \\
\text { wealth } \\
\text { (3) }\end{array}$ & $\begin{array}{l}\text { Company and } \\
\text { Individual } \\
\text { prediction and } \\
\text { wealth } \\
\text { (4) }\end{array}$ \\
\hline \multicolumn{5}{|l|}{$\mathrm{NH}$} \\
\hline Insurance company prediction & $\begin{array}{c}0.400 * * * \\
(0.021)\end{array}$ & $\begin{array}{c}0.396 * * * \\
(0.021)\end{array}$ & $\begin{array}{c}0.376^{* * *} \\
(0.021)\end{array}$ & $\begin{array}{c}0.370 * * * \\
(0.021)\end{array}$ \\
\hline Individual prediction & & $\begin{array}{c}0.041 * * \\
(0.020)\end{array}$ & & $\begin{array}{c}0.046 * * \\
(0.020)\end{array}$ \\
\hline Preventive health activity & & & $\begin{array}{c}-0.039 * * \\
(0.018)\end{array}$ & $\begin{array}{c}-0.041 * * \\
(0.018)\end{array}$ \\
\hline Always wear seat belt & & & $\begin{array}{c}-0.025 * * \\
(0.012)\end{array}$ & $\begin{array}{c}-0.026^{* *} \\
(0.012)\end{array}$ \\
\hline Top quartile of assets & & & $\begin{array}{c}-0.028 * \\
(0.016)\end{array}$ & $\begin{array}{c}-0.027 * \\
(0.016)\end{array}$ \\
\hline $3^{\text {rd }}$ Wealth quartile & & & $\begin{array}{l}-0.015 \\
(0.016)\end{array}$ & $\begin{array}{l}-0.016 \\
(0.016)\end{array}$ \\
\hline $2^{\text {nd }}$ Wealth quartile & & & $\begin{array}{c}0.006 \\
(0.016)\end{array}$ & $\begin{array}{c}0.006 \\
(0.016)\end{array}$ \\
\hline LTCI & & & & \\
\hline Insurance company prediction & $\begin{array}{c}-0.129 * * * \\
(0.023)\end{array}$ & $\begin{array}{c}-0.143 * * * \\
(0.023)\end{array}$ & $\begin{array}{c}-0.076^{* * *} \\
(0.023)\end{array}$ & $\begin{array}{c}-0.091 * * * \\
(0.023)\end{array}$ \\
\hline Individual prediction & & $\begin{array}{c}0.100 * * * \\
(0.017)\end{array}$ & & $\begin{array}{c}0.094 * * * \\
(0.017)\end{array}$ \\
\hline Preventive health activity & & & $\begin{array}{l}0.029 * \\
(0.017)\end{array}$ & $\begin{array}{c}0.023 \\
(0.017)\end{array}$ \\
\hline Always wear seat belt & & & $\begin{array}{c}0.041 * * * \\
(0.012)\end{array}$ & $\begin{array}{c}0.041 * * * \\
(0.012)\end{array}$ \\
\hline Top quartile of assets & & & $\begin{array}{c}0.105^{* * *} \\
(0.015)\end{array}$ & $\begin{array}{c}0.104 * * * \\
(0.015)\end{array}$ \\
\hline $3^{\text {rd }}$ Wealth quartile & & & $\begin{array}{c}0.075^{* * *} \\
(0.016)\end{array}$ & $\begin{array}{c}0.074 * * * \\
(0.016)\end{array}$ \\
\hline $2^{\text {nd }}$ Wealth quartile & & & $\begin{array}{c}0.049 * * * \\
(0.016)\end{array}$ & $\begin{array}{c}0.048 * * * \\
(0.016)\end{array}$ \\
\hline Number of observations & 5,000 & 5,000 & 5,000 & 5,000 \\
\hline
\end{tabular}

Notes: Table reports marginal effects of marginal success probability of entering nursing home and long-tern care insurance coverage from bivariate probit estimation of equation (2) and (5).

$* * *, * *,{ }^{*}$ denote statistical significance at the $1 \%, 5 \%$, and $10 \%$ level, respectively.

Our estimates are weighted using the 1995 household weights. 
Table A2: Two-type Model: Marginal Effects

\begin{tabular}{|c|c|c|c|c|}
\hline & \multicolumn{2}{|c|}{ Company predictor only } & \multicolumn{2}{|c|}{ Company \& Individual predictors } \\
\hline \multicolumn{5}{|l|}{ Type (timid type $=1)$} \\
\hline \multirow[t]{2}{*}{ Preventive health activity } & \multirow{2}{*}{\multicolumn{2}{|c|}{$\begin{array}{l}0.106^{*} \\
(0062)\end{array}$}} & \multicolumn{2}{|c|}{0.097} \\
\hline & & & \multicolumn{2}{|c|}{$(0.061)$} \\
\hline \multirow[t]{2}{*}{ Always wear seat belt } & \multicolumn{2}{|c|}{$0.127 * *$} & \multicolumn{2}{|c|}{$0.131 * *$} \\
\hline & \multicolumn{2}{|c|}{$(0.056)$} & \multicolumn{2}{|c|}{$(0.057)$} \\
\hline \multirow[t]{2}{*}{ Top quartile of assets } & \multicolumn{2}{|c|}{$0.276^{* * *}$} & \multicolumn{2}{|c|}{$0.286 * * *$} \\
\hline & \multicolumn{2}{|c|}{$(0.099)$} & \multicolumn{2}{|c|}{$(0.100)$} \\
\hline \multirow[t]{2}{*}{$3^{\text {rd }}$ Wealth quartile } & \multicolumn{2}{|c|}{$0.195 * *$} & \multicolumn{2}{|c|}{$0.201 * *$} \\
\hline & \multicolumn{2}{|c|}{$(0.080)$} & \multicolumn{2}{|c|}{$(0.080)$} \\
\hline \multirow[t]{3}{*}{$2^{\text {nd }}$ Wealth quartile } & \multirow{2}{*}{\multicolumn{2}{|c|}{$\begin{array}{l}0.118^{*} \\
(0.062)\end{array}$}} & \multirow{2}{*}{\multicolumn{2}{|c|}{$\begin{array}{l}0.121 * \\
(0.062)\end{array}$}} \\
\hline & & & & \\
\hline & Timid type & Bold type & Timid type & Bold type \\
\hline \multicolumn{5}{|l|}{$\mathbf{N H}$} \\
\hline \multirow[t]{2}{*}{ Insurance company prediction } & $0.555^{*}$ & $1.273 * * *$ & $0.560 *$ & $1.237 * * *$ \\
\hline & $(0.307)$ & $(0.206)$ & $(0.306)$ & $(0.207)$ \\
\hline \multirow[t]{2}{*}{ Individual prediction } & & & 0.078 & $0.132 * * *$ \\
\hline & & & $(0.068)$ & $(0.042)$ \\
\hline \multicolumn{5}{|l|}{ LTCI } \\
\hline \multirow[t]{2}{*}{ Insurance company prediction } & $-0.159 * * *$ & $-0.470 *$ & $-0.200 * * *$ & $-0.552 *$ \\
\hline & $(0.040)$ & $(0.216)$ & $(0.053)$ & $(0.239)$ \\
\hline \multirow[t]{2}{*}{ Individual prediction } & & & 0.278 & $0.544 * * *$ \\
\hline & & & $(0.196)$ & $(0.059)$ \\
\hline Number of Obs & 5,000 & & 5,000 & \\
\hline
\end{tabular}

Notes: Table reports marginal effects of marginal success probability of entering nursing home and long-tern care insurance coverage from two-type model of equation (8), (9) and (13).

For the type equation, we estimate the marginal success probability of being timid type.

$* * *, * *, *$ denote statistical significance at the $1 \%, 5 \%$, and $10 \%$ level, respectively.

Standard errors are calculated by Monte Carlo simulation. 